\title{
Relationship between fear of falling and mobility varies with visual function among older adults
}

\author{
Orna A Donoghue, ${ }^{1}$ Harriet Ryan, ${ }^{3}$ Eoin Duggan, ${ }^{4}$ Ciaran Finucane,${ }^{1}$ George M Savva, ${ }^{1}$ Hilary Cronin,${ }^{1}$ \\ James Loughman ${ }^{5,6}$ and Rose Anne Kenny, \\ ${ }^{1}$ The Irish Longitudinal Study on Ageing, ${ }^{2}$ Trinity College Institute of Neuroscience, Trinity College Dublin, ${ }^{3}$ School of Medicine, Royal \\ College of Surgeons in Ireland, ${ }^{4}$ School of Medicine and Medical Sciences, University College Dublin, ${ }^{5}$ Department of Optometry, School of \\ Physics, Dublin Institute of Technology, Dublin, Ireland; and ${ }^{6}$ African Vision Research Institute, Faculty of Sciences and Health, University \\ of KwaZulu Natal, Durban, South Africa
}

\begin{abstract}
Aim: The present study examined the association between vision, fear of falling and fear-related activity restriction, and assessed the effect of vision on the relationship between fear of falling and mobility, using data from a nationally representative sample of community-dwelling adults aged $\geq 50$ years.

Methods: Participants $(n=5003)$ completed an interview and health assessment (including Timed Up-and-Go, vision and cognitive tests). Visual acuity and contrast sensitivity were assessed using an Early Treatment Diabetic Retinopathy Study logMAR chart and Functional Vision Analyzer, respectively. Participants self-reported their vision as excellent, very good, good, fair or poor. They were assigned to no fear of falling, fear without activity restriction and fear with activity restriction groups. Logistic regression models examined the relationship between vision, fear of falling and activity restriction. Linear regression models were used to examine the main and interaction effects of fear of falling, self-reported vision, visual acuity, and contrast sensitivity on mobility after adjusting for confounders.
\end{abstract}

Results: Poorer self-reported vision was independently associated with fear of falling and fear-related activity restriction $(P<0.05)$, but visual acuity and contrast sensitivity were not. Participants with the lowest visual acuity and contrast sensitivity levels, combined with fear-related activity restriction, had slower Timed Up-and-Go than those in the highest visual performance quartiles $(P<0.05)$.

Conclusions: Participants' perceptions of visual function were related to fear of falling and activity restriction, but this was not explained by other visual factors measured here. However, poorer visual acuity and contrast sensitivity did moderate the relationship between fear-related activity restriction and mobility, highlighting the importance of a comprehensive vision assessment especially in individuals with fear of falling. Geriatr Gerontol Int 2013; ••: $\bullet \bullet-\bullet$.

Keywords: accidental falls, aged, contrast sensitivity, gait, locomotion.

\section{Introduction}

Fear of falling (FOF) has been defined as "a lasting concern about falling that leads to an individual avoiding activities that he/she remains capable of performing". ${ }^{1}$ It affects up to $30 \%$ of community-dwelling older adults, ${ }^{2,3}$ and occurs in those with and without a history

Accepted for publication 8 September 2013.

Correspondence: Dr Orna Donoghue $\mathrm{PhD}$, The Irish Longitudinal Study on Ageing (TILDA), Lincoln Gate, Trinity College Dublin, Dublin 2, Ireland. Email: odonogh@tcd.ie of falls. It is more common in females, and is independently associated with previous falls, depression, poor self-reported health, reduced social activity and impaired mobility. ${ }^{4-8}$ The consequences of fear-related activity restriction include a decline in physical and social function, which can increase the risk of mobility decline, falls and functional disability. ${ }^{9,10}$

Visual impairment can include deficits in visual acuity (VA), contrast sensitivity (CS), visual field (VF) and depth perception (DP). Lower VA, CS and VF have been associated with poorer mobility in communitydwelling adults, ${ }^{11-16}$ whereas deficits in VA, CS, VF and DP have been associated with falls, especially recurrent falls. ${ }^{17-21}$ 
Estimates of the effect of vision on FOF and activity restriction have been mixed. No independent relationship between self-reported visual impairment and FOF or associated activity restriction was seen in community representative samples; ${ }^{22,23}$ however, moderate and severe self-reported visual impairments were independently associated with FOF-related activity restriction among community-dwelling older adults in receipt of home care services. ${ }^{24}$ Deshpande et al. found that psychophysically measured visual function, specifically CS and VA, was not linked to FOF; however, reduced CS was associated with FOF-related activity restriction among those without depressive symptoms. ${ }^{25}$ Finally, longitudinal studies have shown that reduced VA predicts the development of $\mathrm{FOF}^{18}$ and mobility impairment $^{26}$ after 5 years.

Currently, studies examining associations between FOF, vision and mobility are limited. Both FOF and poor vision have been associated with impaired mobility, but it is unclear how visual impairment and FOF interact with respect to mobility impairment, and if so, which components of vision are most important. Understanding this would allow specific groups to be identified and targeted for assessment and intervention. Therefore, the aims of the present study were first, to examine the role of vision (self-reported vision, VA and $\mathrm{CS}$ ) in FOF and FOF-related activity restriction, and second, to examine the influence of vision in the relationship between FOF and mobility, using data from a nationally representative sample of communitydwelling adults aged 50 years and older.

\section{Methods}

\section{Study design}

The Irish Longitudinal Study on Aging (TILDA) is a prospective cohort study of the social, economic and health circumstances of community-dwelling older adults in Ireland. Analysis is based on the first wave of data, collected between October 2009 and July 2011. The sampling frame is the Irish Geodirectory, a listing of all residential addresses in the Republic of Ireland. A clustered sample of addresses was chosen, and household residents aged $\geq 50$ years and their spouses/ partners (of any age) were eligible to participate. Ethical approval was obtained from the Trinity College Dublin Research Ethics Committee, and participants provided written informed consent.

The study design is described elsewhere. ${ }^{27}$ Briefly, data collection included: (i) a computer-assisted personal interview that included detailed questions on sociodemographics, wealth, health, lifestyle, social support and participation, use of health and social care, and attitudes to aging; (ii) a self-completion questionnaire; and (iii) a detailed health assessment carried out by research nurses including cognitive, cardiovascular, mobility, strength, bone and vision tests. In total, 8175 individuals aged $\geq 50$ years were interviewed, of whom 5037 attended the health center assessment (61.3\%). Inclusion criteria for this analysis was a Mini-Mental State Examination (MMSE) score $\geq 18$, no history of Parkinson's disease, Alzheimer's disease or dementia, participation in a health center assessment, and completion of the FOF and activity restriction questions in the interview $(n=5003)$.

\section{Outcome measures}

\section{Demographics and health}

Age, sex and highest level of education attained were recorded. Primary, secondary and tertiary education corresponded to $\leq 8,9-13$ and $\geq 13$ years of education, respectively. Height and weight were measured, and body mass index (BMI) was calculated. Participants selfreported doctor-diagnosed chronic conditions from the following: heart attack or heart failure or angina, stroke, diabetes, chronic lung disease, asthma, arthritis, osteoporosis, cancer, peptic ulcer, hip fracture, hypertension and high cholesterol. The number of medications was also recorded. Depressive symptoms were assessed using the 20-item Center for Epidemiological Studies Depression (CES-D) scale, where a score of $\geq 16$ represents clinically relevant depressive symptoms. ${ }^{28}$

\section{Fear of falling and falls}

Fear of falling was assessed with the question "Are you afraid of falling?". Those that answered "Yes" were asked "Do you ever limit your activities, for example, what you do or where you go, because you are afraid of falling?". It should be noted that this latter question might combine both physical and social activity limitations. Similar questions have been used in previous studies, ${ }^{3,23,29}$ and allowed participants to be classified into three groups: (i) no FOF; (ii) FOF, but no activity restrictions (FOF-NAR); and (iii) FOF with activity restrictions (FOF-AR). Participants were also asked how many times they had fallen in the previous year.

\section{Cognitive function}

Participants completed the MMSE, ${ }^{30}$ which assesses global cognition (maximum score 30). A letter fluency task (list as many words as possible beginning with " $\mathrm{F}$ " in $1 \mathrm{~min}$ ) measured expressive language and executive function, ${ }^{31}$ and a computer-based choice reaction time test measured processing speed. ${ }^{32}$ In this test, participants depressed a button, released it in response to an on-screen stimulus and pressed the appropriate target button (this occurred approximately 100 times). The 
mean time from appearance of the stimulus to pressing this button was the choice reaction time. Both verbal fluency and choice reaction time have been shown to be independent predictors of Timed Up-and-Go (TUG) performance. $^{33}$

\section{Physical function}

Maximum grip strength was the highest score from two tests on each hand using a Baseline hydraulic hand dynamometer (Fabrication Enterprises, White Plains, NY, USA). Grip strength declines with age and indicates overall strength. ${ }^{34}$ Mobility was assessed with the TUG test using a chair with armrests and seat height of $46 \mathrm{~cm}$. Participants were asked to rise from the chair, walk $3 \mathrm{~m}$ at normal pace, turn around, walk back and sit down again. ${ }^{35}$ Walking aids were allowed, and no instructions were given about the use of participants' arms. The time taken from the command "Go" to when the participant sat with their back resting against the back of the chair was recorded using a stopwatch.

\section{Vision}

Participants self-reported their vision as excellent, very good, good, fair or poor; ${ }^{36}$ one participant reported being registered blind and was added to the poor vision group. A history of cataracts and related surgery, glaucoma and age related macular degeneration (ARMD) was also recorded.

VA represents a high contrast letter recognition task, and was assessed using an Early Treatment Diabetic Retinopathy Study (ETDRS) logMAR chart (Precision Vision, La Salle, IL, USA) at a viewing distance of $4 \mathrm{~m} .{ }^{37,38}$ VA was measured psychophysically for both eyes, using the habitual distance vision correction if required. For statistical purposes, the best acuity value measured from either eye was selected and converted to a Visual Acuity Score (VAS). ${ }^{38}$ This score inverts the $\log$ MAR scale using the formula: VAS $=100-$ $50 \times \log \mathrm{MAR}$, so that a VAS of 100 represents a $\log$ MAR score of 0 or 20/20 vision. For each letter that is read correctly using the ETDRS chart, there is a corresponding 1-point increase in the VAS. This allows a more intuitive interpretation of the acuity scores, as higher values indicate better acuity. The VAS was subsequently expressed in quartiles and deciles.

CS represents the ability to distinguish an object from the background in varying size and contrast conditions. It was measured in the eye with better VA using a Functional Vision Analyser (Stereo Optical, Chicago, IL, USA) under mesopic $\left(3 \mathrm{~cd} / \mathrm{m}^{2}\right)$ background illumination conditions. Testing was then repeated for the same background illumination conditions, but in the presence of a radial glare source. ${ }^{39}$ During the test, the respondent viewed a Functional Acuity Contrast
Test (FACT), which comprised sinusoidal gratings presented as Gabor patches at five spatial frequencies of $1.5,3,6,12$ and 18 cycles per degree (cpd) respectively. For each spatial frequency, a series of nine patches were presented in order of decreasing contrast $(0.15 \log$ unit or $50 \%$ loss of contrast between consecutive patches). Respondents were instructed to indicate if the gratings tilted to the left $\left(+15^{\circ}\right)$, right $\left(-15^{\circ}\right)$ or upright $\left(0^{\circ}\right)$, moving from patch 1 to 9 for each spatial frequency tested, in order of increasing frequency. The CS score corresponds to the contrast of the last grating that was accurately identified on each row.

Factor analysis was used to reduce the dimension of the $10 \mathrm{CS}$ scores (each of five frequencies in two glare conditions). As the CS variables are based on ordinal scores, factor analysis using a polychoric correlation matrix was carried out. Two factors were identified and retained based on their eigenvalues and amount of variance explained $(69.2 \%$ in total). Oblique rotation using the direct oblimin criterion suggested two factors corresponding to the contrast sensitivity at high spatial frequencies $(6,12,18 \mathrm{cpd})$ and low spatial frequencies $(1.5,3,6 \mathrm{cpd})$. CS at the middle spatial frequency (6 cpd) loaded onto both factors (Table 1). No factor separated the glare from the "no glare" condition. Two factor scores were derived for each individual corresponding to their "high frequency" and "low frequency" CS. Each factor score was divided into quartiles and deciles for use as independent variables in regression analyses.

\section{Statistical analysis}

Statistical tests were carried out using Stata v12 (StataCorp LP, College Station, TX, USA). All analyses were weighted with respect to age, sex and education to the Quarterly National Household Survey (2010) to ensure that data were nationally representative. Data were further weighted by health status (self-reported health, disability status) and sociodemographic factors (age, education) to account for those who did not attend a health assessment. Baseline characteristics of each group were compared using regression analysis and $\chi^{2}$-tests.

Logistic regression analysis was used to examine the relationship of vision with FOF and FOF-related activity restriction. VA, CS factors 1 and 2 (all expressed as deciles), and self-reported vision were entered into separate models, which also included the effects of age, sex and education.

Linear regression was then used to examine the associations between FOF groups and TUG before and after adjusting for age, sex, education, BMI, chronic conditions, medications, history of falls in the previous year, CES-D score, letter fluency, choice reaction time, maximum grip strength and doctor-diagnosed cataracts 
JOBNAME: No Job Name PAGE: 4 SESS: 9 OUTPUT: Wed Oct 9 15:41:42 2013 SUM: 96757A6C

/Xpp84/wiley_journal/GGI/ggi_v0_i0/ggi_12174

OA Donoghue et al.

Table 1 Rotated factor loadings and unique variance for each contrast sensitivity variable

\begin{tabular}{lcll}
\hline & $\begin{array}{l}\text { Factor 1 } \\
\text { (high spatial } \\
\text { frequencies) }\end{array}$ & $\begin{array}{l}\text { Factor 2 } \\
\text { (low spatial } \\
\text { frequencies) }\end{array}$ & $\begin{array}{l}\text { Unique } \\
\text { variance }\end{array}$ \\
\hline CS (no glare) & & & \\
1.5 cpd & -0.1555 & 0.7598 & 0.5312 \\
3 cpd & 0.088 & 0.7823 & 0.3029 \\
6 cpd & 0.4526 & 0.472 & 0.3324 \\
12 cpd & 0.839 & 0.0079 & 0.2885 \\
18 cpd & 0.6489 & -0.1213 & 0.6526 \\
CS (glare) & & & \\
1.5 cpd & -0.0798 & 0.78 & 0.4551 \\
3 cpd & 0.1751 & 0.7176 & 0.3133 \\
6 cpd & 0.5783 & 0.3742 & 0.2825 \\
12 cpd & 0.8757 & -0.0286 & 0.2604 \\
18 cpd & 0.6793 & 0.025 & 0.5189 \\
\hline
\end{tabular}

High loadings $(\geq 0.3)$ are shown in bold. cpd, cycles per degree; CS, contrast sensitivity.

(treated or untreated), glaucoma and ARMD. TUG was not normally distributed and was therefore log transformed for analysis.

Next, the visual variables (self-reported vision and quartiles of VA, high and low frequency CS) were added to the regression models separately and simultaneously to assess the independent effect of each aspect of visual function on mobility, and to explore whether visual impairment mediated any of the relationship between FOF and mobility.

Finally, moderation effects were examined by adding interaction terms between FOF and each vision variable to the regression models. Marginal mean TUG times from these models were plotted to graphically explore these interactions after adjusting for all covariates.

Complete data was available for 4498 participants $(89.9 \%)$, and complete case analysis was used for multivariate analyses. Significance level was set at $P<0.05$.

\section{Results}

Baseline characteristics of the no FOF $(n=3974)$, FOFNAR $(n=727)$ and FOF-AR $(n=302)$ groups are provided in Table 2. Both FOF groups had more participants aged $\geq 75$ years, were more likely to be female, have greater comorbidities and poorer physical health, mental health, cognitive function, and visual function than the no FOF group $(P<0.001)$. Most pronounced differences were observed in the FOF-AR group.

Psychophysical measures of vision (deciles of VA and CS) were not associated with FOF after adjusting for age, sex and education $(P>0.05$; Fig. 1). However, there was a statistically significant worsening of FOF with poorer self-reported vision. This was particularly marked among those who rated their vision as "fair" or "poor" $(P<0.05)$. An identical relationship was observed for FOF-related activity restriction.

Both FOF groups had slower TUG times than the no FOF group in univariate and multivariate analysis $(P<0.001$; models 1 and 2 , Table 3$)$. The exponent of additive coefficients for $\log$ (TUG) can be interpreted as multiplicative coefficients for TUG, and so the coefficients in Table 3 correspond to those in the FOF-NAR group completing TUG 3.8\% more slowly than those without FOF, whereas those with FOF-related activity restriction completed TUG $13.7 \%$ more slowly.

Poorer self-reported vision was independently associated with slower TUG after adjusting for all covariates $(P<0.05)$, whereas VA and CS had no independent effect on TUG performance (results not shown). Similar effects were observed when all psychophysical and selfreported vision variables were entered simultaneously (model 3, Table 3). However, adjusting for these vision variables had little effect on the FOF coefficients, and therefore did not explain the relationship between FOF, activity restriction and mobility.

Interaction effects for FOF with VA, high frequency and low frequency CS were statistically significant in the FOF-AR group $(P<0.001)$, but interaction effects with self-reported vision were not (Fig. 2). Specifically, marginal interaction plots adjusting for covariates show that individuals with FOF-related activity restriction who were in the lowest quartile of VA and CS had slower TUG than those in the highest quartiles $(P<0.05)$.

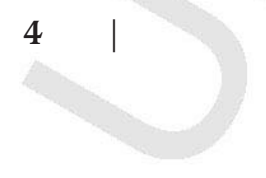


JOBNAME: No Job Name PAGE: 5 SESS: 9 OUTPUT: Wed Oct 9 15:41:42 2013 SUM: 1558AEA7

/Xpp84/wiley_journal/GGI/ggi_v0_i0/ggi_12174

Fear of falling, vision and mobility

Table 2 Baseline characteristics of no fear of falling, fear of falling with activity restriction and fear of falling with no activity restriction groups

\begin{tabular}{|c|c|c|c|c|}
\hline & $\begin{array}{l}\text { no FOF } \\
(n=3974) \\
\text { Mean } \pm \text { SD / n (\%) }\end{array}$ & $\begin{array}{l}\text { FOF-NAR } \\
(n=727) \\
\text { Mean } \pm \text { SD / n (\%) }\end{array}$ & $\begin{array}{l}\text { FOF-AR } \\
(n=302) \\
\text { Mean } \pm \text { SD / n (\%) }\end{array}$ & $\begin{array}{l}\text { Total } \\
(n=5003) \\
\text { Mean } \pm \text { SD / n (\%) }\end{array}$ \\
\hline \multicolumn{5}{|l|}{ Age (years) } \\
\hline $50-64$ & $2657(64.1)$ & $396(46.9)$ & $159(43.8)$ & $3212(59.8)$ \\
\hline $65-74$ & $1016(22.8)$ & $217(23.4)^{* * * * *}$ & $98(25.6)^{* * * * *}$ & $1331(23.1)$ \\
\hline$\geq 75$ & $301(13.1)$ & $114(29.7)$ & $45(30.6)$ & 460 (17.1) \\
\hline Sex (female) & $1938(45.3)$ & $557(76.1)^{* * * * *}$ & $218(71.4)^{* * * *}$ & $2713(52.2)$ \\
\hline \multicolumn{5}{|l|}{ Education (\%) } \\
\hline Primary & $805(33.7)$ & $190(45.9)$ & $94(51.9)$ & $1089(37.0)$ \\
\hline Secondary & $1675(45.8)$ & $300(39.5) * *$ & $117(35.5)^{* * * *}$ & $2092(44.0)$ \\
\hline Tertiary & $1492(20.5)$ & $237(14.6)$ & $91(12.6)$ & $1820(19.0)$ \\
\hline BMI $\left(\mathrm{kg} / \mathrm{m}^{2}\right)$ & $28.54 \pm 4.78$ & $29.10 \pm 5.51 *$ & $29.49 \pm 5.86 *$ & $28.70 \pm 5.00$ \\
\hline \multicolumn{5}{|l|}{ Chronic conditions } \\
\hline 1 condition & $1199(29.4)$ & $189(23.9)$ & 49 (13.6) & $1437(27.3)$ \\
\hline 2 conditions & $881(22.5)$ & $192(24.3) * \%$ & $75(21.1)^{\% * \%}$ & $1148(22.7)$ \\
\hline$\geq 3$ conditions & $859(23.4)$ & $234(38.6)$ & $143(56.0)$ & $1236(28.3)$ \\
\hline Medications & $1.23 \pm 1.08$ & $1.71 \pm 1.04^{* * * *}$ & $2.08 \pm 1.01 \% * \%$ & $1.37 \pm 1.10$ \\
\hline \multicolumn{5}{|l|}{ History of falls (\%) } \\
\hline 1 fall & $467(11.8)$ & $133(16.8)$ & $52(18.2)$ & $652(13.1)$ \\
\hline$\geq 2$ falls & $205(5.4)$ & $86(11.9)^{* * *}$ & $49(14.3)^{* \% *}$ & $340(7.1)$ \\
\hline Depressive symptoms & $5.06 \pm 6.34$ & $7.93 \pm 8.47$ 先* & $10.94 \pm 10.21 \% * \%$ & $5.96 \pm 7.29$ \\
\hline MMSE & $28.37 \pm 1.87$ & $28.13 \pm 2.05$ & $27.72 \pm 1.99$ \%䊼 & $28.28 \pm 1.92$ \\
\hline Letter fluency & $11.53 \pm 5.00$ & $10.62 \pm 4.61$ 苵* & $10.79 \pm 5.03 *$ & $11.33 \pm 4.96$ \\
\hline Choice reaction time (ms) & $825 \pm 280$ & $907 \pm 370 \%$ & $935 \pm 320 \% * \%$ & $846 \pm 301$ \\
\hline Max grip strength (kg) & $28.65 \pm 9.95$ & $21.83 \pm 8.24 \% * \%$ & $21.17 \pm 9.12^{\text {米前 }}$ & $26.99 \pm 10.09$ \\
\hline TUG (s) & $8.58 \pm 1.81$ & $9.72 \pm 2.57 \% * *$ & $11.41 \pm 5.05^{\text {关关 }}$ & $8.97 \pm 2.46$ \\
\hline Cataracts - with surgery (\%) & $160(4.9)$ & $53(12.8)$ & $28(13.1)$ & $241(6.8)$ \\
\hline Cataracts - no surgery $(\%)$ & $126(4.2)$ & $48(7.1)^{* * * *}$ & $18(7.1)^{* \% *}$ & $192(4.9)$ \\
\hline Glaucoma (\%) & $71(1.9)$ & $21(3.5)$ & $13(5.3)^{* *}$ & $105(2.4)$ \\
\hline $\operatorname{ARMD}(\%)$ & $57(1.7)$ & $22(3.4)^{*}$ & $5(1.2)$ & $84(2.0)$ \\
\hline \multicolumn{5}{|l|}{ Self-reported vision (\%) } \\
\hline Excellent & $894(19.7)$ & $121(14.7)$ & $48(11.3)$ & $1063(18.2)$ \\
\hline Very good & $1522(37.8)$ & $287(36.7)$ & $100(29.0)$ & $1909(37.0)$ \\
\hline Good & $1273(33.4)$ & $255(36.3)$ & $104(35.5) * \% *$ & $1632(34.1)$ \\
\hline Fair & $252(7.6)$ & $53(9.7)$ & $39(15.9)$ & $344(8.6)$ \\
\hline Poor & $33(1.4)$ & $11(2.6)$ & $11(8.3)$ & $55(2.1)$ \\
\hline VA (VAS) & $96 \pm 10$ & $95 \pm 10 \%$ & $93 \pm 9 * \% *$ & $96 \pm 10$ \\
\hline \multicolumn{5}{|l|}{ CS (no glare) } \\
\hline $1.5 \mathrm{cpd}$ & $36.4 \pm 19.9$ & $34.9 \pm 21.1$ & $34.0 \pm 20.8$ & $36.0 \pm 20.2$ \\
\hline $3 \mathrm{cpd}$ & $67.2 \pm 32.0$ & $62.7 \pm 31.3 *$ & $58.6 \pm 34.3 * *$ & $65.9 \pm 32.2$ \\
\hline $6 \mathrm{cpd}$ & $31.9 \pm 25.6$ & $28.0 \pm 24.5 \%$ & $26.1 \pm 25.8 * \%$ & $30.8 \pm 25.5$ \\
\hline $12 \mathrm{cpd}$ & $6.6 \pm 9.6$ & $5.0 \pm 9.1 * \% *$ & $5.2 \pm 14.1$ & $6.2 \pm 9.9$ \\
\hline $18 \mathrm{cpd}$ & $0.8 \pm 2.7$ & $0.6 \pm 2.0^{*}$ & 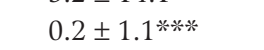 & $0.7 \pm 2.5$ \\
\hline \multicolumn{5}{|l|}{ CS (glare) } \\
\hline $1.5 \mathrm{cpd}$ & $38.2 \pm 19.1$ & $35.4 \pm 18.1 \%$ & $33.9 \pm 19.6 * *$ & $37.5 \pm 19.0$ \\
\hline $3 \mathrm{cpd}$ & $69.4 \pm 32.8$ & $63.9 \pm 32.1 \%$ & $57.1 \pm 33.8^{* \% *}$ & $67.6 \pm 33.0$ \\
\hline $6 \mathrm{cpd}$ & $32.2 \pm 25.1$ & $28.7 \pm 25.4 \%$ & $24.3 \pm 22.5$ \%** & $31.1 \pm 25.1$ \\
\hline $12 \mathrm{cpd}$ & $6.8 \pm 10.2$ & $5.6 \pm 9.5 \%$ & $4.2 \pm 7.6$ 类前 & $6.5 \pm 9.9$ \\
\hline $18 \mathrm{cpd}$ & $0.8 \pm 2.7$ & $0.6 \pm 2.8 *$ & $0.2 \pm 1.0^{\% * \%}$ & $0.7 \pm 2.6$ \\
\hline
\end{tabular}

* $P<0.05 ;{ }^{*} P<0.01 ; * * * P<0.001$. Prevalence is weighted by age, sex and education to the Quarterly National Household Survey (2010) to ensure that data were nationally representative and further weighted by health status and sociodemographic factors to account for those who did not attend a health assessment. Regression analysis for continuous variables; chi squared analysis for categorical variables. No fear of falling (FOF) group was compared to the fear of falling with no activity restriction (FOF-NAR) group and the fear of falling with activity restriction (FOF-AR) group. ARMD, age-related macular degeneration; BMI, body mass index; cpd, cycles per degree; CS, contrast sensitivity; FOF, fear of falling; MMSE, Mini-Mental State Examination; SD, standard deviation; TUG, Timed Up-and-Go; VA, visual acuity; VAS, visual acuity scale. 
(a)
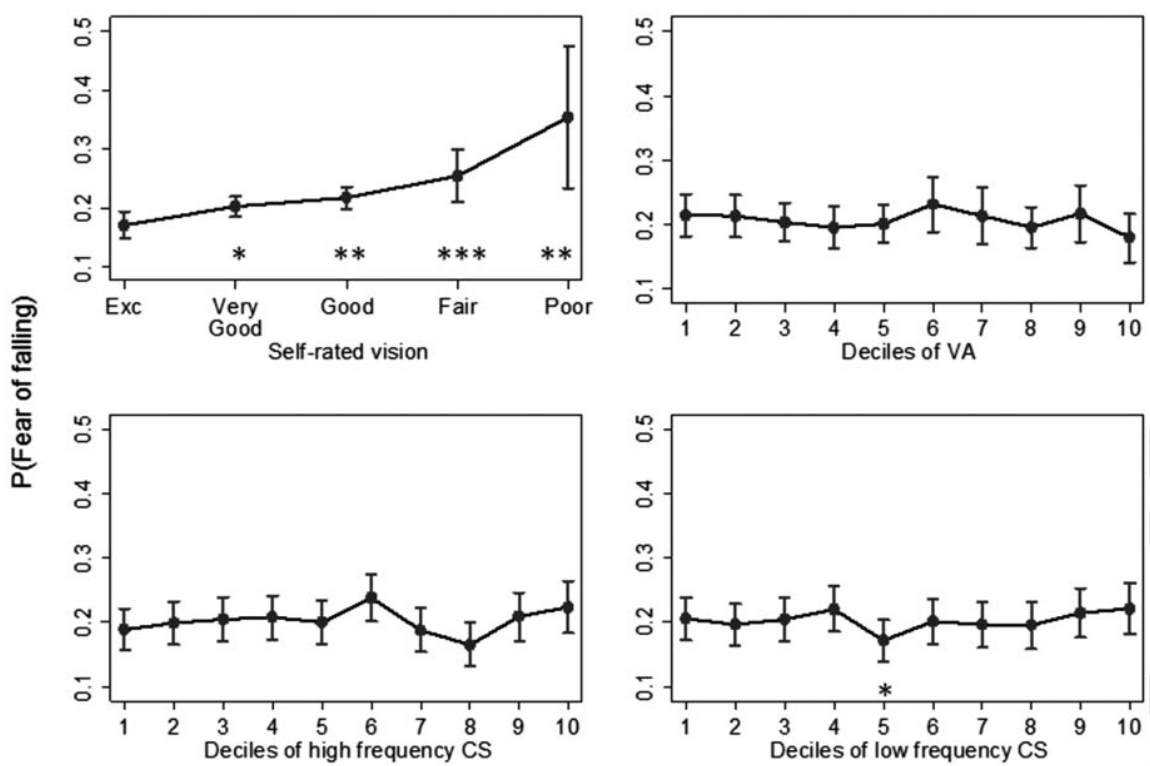

(b)

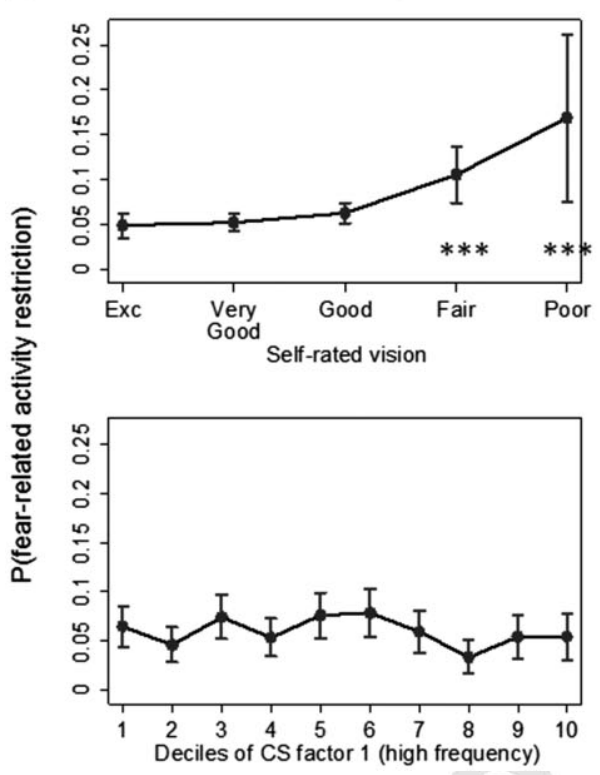

Relationship between vision and fear-related activity restriction
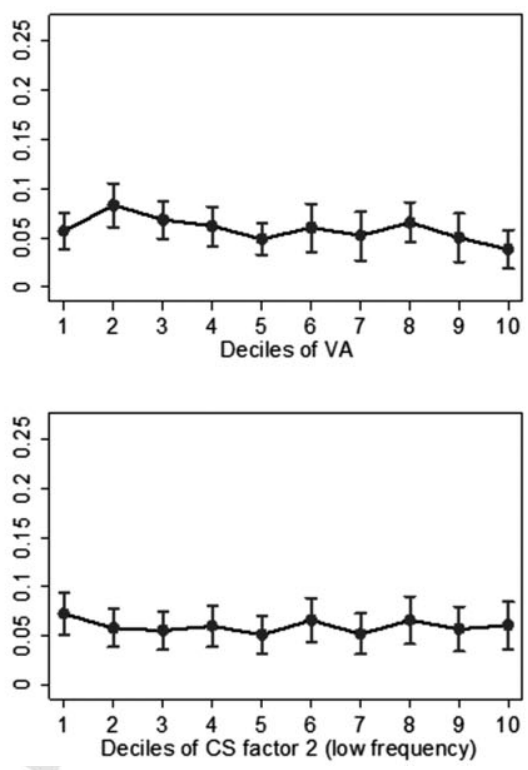

Figure 1 Relationship between (a) vision and fear of falling; (b) vision and fear-related activity restriction. Lowest deciles reflect lowest level of contrast sensitivity (CS) and visual acuity (VA) performance. Logistic regression analysis adjusted for age, sex and education. ${ }^{*} P<0.05$; $* * 001$; *** $P<0.001$ (indicates a category that is a significant predictor of the outcome relative to the highest level of visual function). $\mathrm{P}$ (fear of falling), probability of reporting fear of falling; $\mathrm{P}($ fear-related activity restriction), probability of reporting fear-related activity restriction.

\section{Discussion}

The findings of the current study show that poorer self-reported vision was independently associated with FOF and FOF-related activity restriction, but that psychophysically measured vision (VA, CS) was not. FOF and self-reported vision were also linked to mobility impairment, but mesopic and photopic vision did not explain much of the relationship between FOF and mobility. These findings show that although participants' perceptions of visual function are related to FOF and activity restriction, other visual (e.g. DP, VF, eye disease) or non-visual factors (e.g. cognitive processing) could be important determinants of self-reported vision.

However, reduced psychophysical visual function was associated with slower TUG in the FOF-related activity restriction group, illustrating the moderating effect of psychophysical vision on the relationship between FOF and mobility. FOF is associated with poorer function across multiple domains (physical, psychological, cognitive), and this is more pronounced in those with activity restriction. It is possible that reduced vision compounds the existing deficits in this group, resulting in greater mobility impairment. Viljainen et al. reported that when multiple self-reported sensory deficits 
Table 3 Univariate and multivariate linear regression showing relationship between fear of falling, vision and $\log$ (Timed Up-and-Go) after adjusting for covariates

\begin{tabular}{|c|c|c|c|}
\hline $\log (\mathrm{TUG})$ & $\begin{array}{l}\text { Model } 1 \\
\beta(95 \% \mathrm{CI})\end{array}$ & $\begin{array}{l}\text { Model } 2 \\
\beta(95 \% \mathrm{CI})\end{array}$ & $\begin{array}{l}\text { Model } 3 \\
\beta(95 \% \mathrm{CI})\end{array}$ \\
\hline No FOF & Reference & Reference & Reference \\
\hline FOF-NAR & $0.113(0.086,0.141) *$ & $0.037(0.017,0.058) * * *$ & $0.034(0.012,0.055)^{* *}$ \\
\hline FOF-AR & $0.237(0.183,0.290) * * *$ & $0.128(0.084,0.172) *$ & $0.115(0.073,0.158) * * *$ \\
\hline \multicolumn{4}{|l|}{ Self-reported vision } \\
\hline Excellent & - & - & Reference \\
\hline Very good & - & - & $0.014(-0.001,0.029)$ \\
\hline Good & - & - & $0.017(0.001,0.033) *$ \\
\hline Fair & - & - & $0.040(0.009,0.071)^{*}$ \\
\hline Poor & - & - & $0.097(0.020,0.175)^{*}$ \\
\hline \multicolumn{4}{|l|}{ VA (VAS) } \\
\hline Lowest (20-93) & - & - & $-0.018(-0.038,0.002)$ \\
\hline $2^{\text {nd }}$ quartile (94-99) & - & - & $-0.012(-0.029,0.004)$ \\
\hline $3^{\text {rd }}$ quartile (100-103) & - & - & $-0.021(-0.038,-0.004)^{*}$ \\
\hline Highest (104-115) & - & - & Reference \\
\hline \multicolumn{4}{|l|}{ CS factor 1 (high frequencies) } \\
\hline Lowest $(-1.44$ to -0.75$)$ & - & - & $0.002(-0.023,0.029)$ \\
\hline 2nd quartile $(-0.75$ to -0.17$)$ & - & - & $-0.005(-0.027,0.017)$ \\
\hline 3rd quartile $(-0.17$ to 0.54$)$ & - & - & $-0.014(-0.031,0.003)$ \\
\hline Highest ( 0.54 to 7.80$)$ & - & 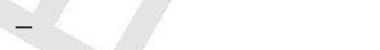 & Reference \\
\hline \multicolumn{4}{|l|}{ CS factor 2 (low frequencies) } \\
\hline Lowest $(-2.29$ to -0.64$)$ & - & - & $0.007(-0.020,0.034)$ \\
\hline 2nd quartile $(-0.64$ to -0.17$)$ & - & - & $0.012(-0.010,0.034)$ \\
\hline 3rd quartile $(-0.17$ to -0.61$)$ & - & - & $0.009(-0.010,0.027)$ \\
\hline Highest $(0.61$ to -3.85$)$ & - & - & Reference \\
\hline
\end{tabular}

$* P<0.05 ; * * 2<0.01$; $* * * 0.001$. Model 1: Unadjusted linear regression. Model 2: Linear regression adjusted for age, sex, body mass index, education, medications, chronic conditions, history of falls, depressive symptoms, choice reaction time, word fluency, maximum grip strength, history of cataracts (treated or untreated), glaucoma, age related macular degeneration. Model 3: all vision variables entered simultaneously and adjusted as for Model 1. $\beta$, coefficient; CI, confidence intervals; cpd, cycles per degree; CS, contrast sensitivity; FOF, fear of falling; FOF-AR, fear of falling with activity restriction; FOF-NAR, fear of falling with no activity restriction; TUG, Timed Up-and-Go; VA, visual acuity; VAS, visual acuity scale.

combined with FOF, there is an increased risk of developing walking difficulties. ${ }^{40}$

The ability to maintain dynamic postural stability requires an interaction between the sensory and motor systems. TUG involves transfers, turning and walking, and therefore requires muscle strength and balance; therefore, it was speculated that vision might play a more important role in this task compared with straight line walking. In challenging balance situations, an individual relies on the visual system, particularly CS and DP, to gain information about body positions, movements and the environment to maintain stability. ${ }^{41} \mathrm{CS}$ might also reflect the ability to detect and recognise objects in the environment, and see ground level obstacles more accurately. ${ }^{42}$ Visual functions, such as VA and CS, decrease with age $e^{43,44}$ as do cognitive processes such as executive function, processing speed and visual attention. ${ }^{45,46}$ Similar cognitive deficits have been observed in recurrent fallers, and could reflect a difficulty in coordination of the visual, cognitive and motor aspects required to negotiate the everyday environment. ${ }^{47}$ If an individual with reduced vision, especially $\mathrm{CS}$, does not detect all of the environmental and body position information available, this might predispose them to cautious gait and/or a greater risk of falling. If a vision deficit is combined with FOF or other age-related factors, such as increased risk of osteoporosis, low muscle tone, poorer muscle strength, slow reaction times and postural instability, the risk of mobility impairment, falls and injury could be amplified even further.

Owsley et al. found that age and CS at $6 \mathrm{cpd}$ were the best predictors of the ability to detect and identify real-world targets, such as faces, signs and objects. ${ }^{48}$ Although the present results suggest that CS at both high and low frequencies are important for mobility, we are unaware of any research that has identified which spatial frequencies relate most closely to specific environmental objects that might affect mobility. 

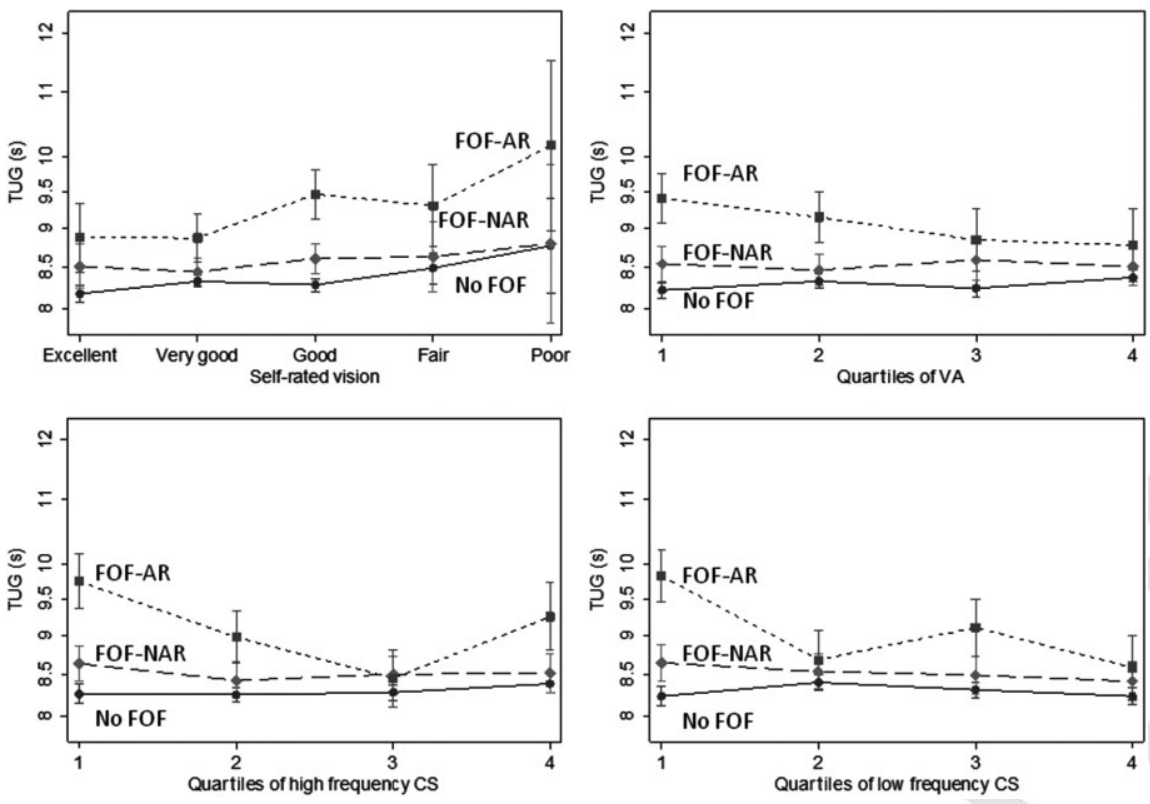

Figure 2 Interaction effects between fear of falling (FOF) and each vision variable with respect to their effect on functional mobility (measured by Timed Up-and-Go [TUG] time). Lowest quartiles reflect lowest level of CS and VA performance.

Linear regression analysis adjusted for age, sex, body mass index, education, medications, chronic conditions, history of falls, depressive symptoms, choice reaction time, word fluency, maximum grip strength, history of cataracts (treated or untreated), glaucoma, age related macular degeneration. cpd, cycles per degree; CS, contrast sensitivity; FOF-AR, fear of falling with activity restriction; FOF-NAR, fear of falling with no activity restriction; VA, visual acuity.

The main strength of the present study was the detailed, psychophysical measures of CS and VA obtained in a large, nationally representative population. However, the study also had some limitations. Given the restraints inherent in a multidisciplinary study of this size (e.g. participant time, cost), a fully comprehensive assessment within each domain was not feasible. Therefore, measures of visual function, such as VF and DP, along with other aspects of sensory function were not obtained, although they have been associated with FOF, falls and mobility in previous research, and therefore might have added to the analysis. Also, only those who attended a health assessment center were included, making the results directly applicable to communitydwelling adults, but not those who are housebound or resident in nursing homes and other facilities. These individuals are likely to have greater mobility limitations and to be in poorer health, so the relationship between FOF, vision and mobility might be different in this group. Finally, CS was tested under mesopic conditions, so the CS results are only directly applicable to low light conditions.

VA is the most commonly measured visual function, but it might not be the best indicator of functional vision. Everyday living involves low contrast conditions, suboptimal lighting and sources of glare, so including CS measurement could provide a more comprehensive visual assessment. Individual variations in CS have direct implications for older adults in terms of environmental modifications (floor surfaces, lighting), behaviors (switching on lights especially at night) and treatment of conditions associated with poor CS (e.g. cataract). Although reduced vision does not affect the mobility of those with no FOF or FOF without activity restriction, it does make those with FOF-related activity restriction more cautious, as evidenced by slower TUG. Reduced vision and FOF can lead to a self-imposed activity restriction, which can lead to social isolation, mobility limitations, loss of independence and increased fall risk. Therefore, the results of the present study suggest that clinicians should consider a comprehensive vision assessment including VA and CS, particularly in individuals with FOF, to prevent this transition to reduced activity.

\section{Acknowledgments}

This work was supported by the Irish Government; Irish Life plc and the Atlantic Philanthropies.

\section{Disclosure statement}

The authors declare no conflict of interest.

\section{References}

1 Tinetti ME, Powell L. Fear of falling and low self-efficacy: a case of dependence in elderly persons. J Gerontol 1993; 48: $35-38$.

2 Friedman SM, Munoz B, West SK, Rubin GS, Fried LP. Falls and fear of falling: which comes first? A longitudinal prediction model suggests strategies for primary and secondary prevention. J Am Geriatr Soc 2002; 50: 1329-1335.

3 Rochat S, Büla CJ, Martin E et al. What is the relationship between fear of falling and gait in well-functioning older persons aged 65 to 70 years? Arch Phys Med Rehabil 2010; 91: 879-884. 
4 Arfken CL, Lach HW, Birge SJ, Miller JP. The prevalence and correlates of fear of falling in elderly persons living in the community. Am J Public Health 1994; 84: 565-570.

5 Austin N, Devine A, Dick I, Prince R, Bruce D. Fear of falling in older women: a longitudinal study of incidence, persistence, and predictors. J Am Geriatr Soc 2007; 55: $1598-1603$.

6 Scheffer AC, Schuurmans MJ, van Dijk N, van der Hooft $\mathrm{T}$, de Rooij SE. Fear of falling: measurement strategy, prevalence, risk factors and consequences among older persons. Age Ageing 2008; 37: 19-24.

7 Vellas BJ, Wayne SJ, Romero LJ, Baumgartner RN, Garry PJ. Fear of falling and restriction of mobility in elderly fallers. Age Ageing 1997; 26: 189-193.

8 Zijlstra GAR, van Haastregt JCM, van Eijk JTM, van Rossum E, Stalenhoef PA, Kempen GIJM. Prevalence and correlates of fear of falling, and associated avoidance of activity in the general population of community-living older people. Age Ageing 2007; 36: 304-309.

9 Delbaere K, Crombez G, Vanderstraeten G, Willems T, Cambier D. Fear-related avoidance of activities, falls and physical frailty. A prospective community-based cohort study. Age Ageing 2004; 33: 368-373.

10 Deshpande N, Metter EJ, Lauretani F, Bandinelli S, Guralnik J, Ferrucci L. Activity restriction induced by fear of falling and objective and subjective measures of physical function: a prospective cohort study. J Am Geriatr Soc 2008; 56: 615-620.

11 Klein BE, Klein R, Lee KE, Cruickshanks KJ. Performancebased and self-assessed measures of visual function as related to history of falls, hip fractures, and measured gait time. The Beaver Dam Eye Study. Ophthalmology 1998; 105: 160-164.

12 Kwan MM-S, Lin S-I, Chen C-H, Close JCT, Lord SR. Sensorimotor function, balance abilities and pain influence Timed Up and Go performance in older community-living people. Aging Clin Exp Res 2011; 23: 196-201.

13 Luiz LC, Rebelatto JR, Coimbra AMV, Ricci NA. Association between visual deficit and clinical-functional characteristics among community-dwelling older adults (Associação entre déficit visual e aspectos clínicofuncionais em idosos da comunidade). Rev Bras 2009; 13: 444-450.

14 West CG, Gildengorin G, Haegerstrom-Portnoy G, Schneck ME, Lott L, Brabyn JA. Is vision function related to physical functional ability in older adults? J Am Geriatr Soc 2002; 50: 136-145.

15 West SK, Rubin GS, Broman AT, Munoz B, Bandeen-Roche K, Turano K. How does visual impairment affect performance on tasks of everyday life? The SEE Project. Salisbury Eye Evaluation. Arch Ophthalmol 2002; 120: $774-780$.

16 Laitinen A, Sainio P, Koskinen S, Rudanko S-L, Laatikainen L, Aromaa A. The association between visual acuity and functional limitations: findings from a nationally representative population survey. Ophthalmic Epidemiol 2007; 14: 333-342.

17 Freeman EE, Muñoz B, Rubin G, West SK. Visual field loss increases the risk of falls in older adults: the salisbury eye evaluation. Invest Ophthalmol Vis Sci 2007; 48: 4445-4450.

18 Klein BEK, Moss SE, Klein R, Lee KE, Cruickshanks KJ. Associations of visual function with physical outcomes and limitations 5 years later in an older population: the Beaver Dam eye study. Ophthalmology 2003; 110: 644-650.

19 Kuang T-M, Tsai S-Y, Hsu W-M, Cheng C-Y, Liu J-H, Chou P. Visual impairment and falls in the elderly: the shihpai eye study. J Chin Med Assoc 2008; 71: 467-472.
20 Lord SR, Dayhew J. Visual risk factors for falls in older people. J Am Geriatr Soc 2001; 49: 508-515.

21 Rossat A, Fantino B, Nitenberg C et al. Risk factors for falling in community-dwelling older adults: which of them are associated with the recurrence of falls? J Nutr Health Aging 2010; 14: 787-791.

22 Howland J, Lachman ME, Peterson EW, Cote J, Kasten L, Jette A. Covariates of fear of falling and associated activity curtailment. Gerontologist 1998; 28: 549-555.

23 Kempen G, van Haastregt J, McKee K, Delbaere K, Zijlstra GR. Socio-demographic, health-related and psychosocial correlates of fear of falling and avoidance of activity in community-living older persons who avoid activity due to fear of falling. BMC Public Health 2009; 9: 170.

24 Fletcher PC, Hirdes JP. Restriction in activity associated with fear of falling among community-based seniors using home care services. Age Ageing 2004; 33: 273-279.

25 Deshpande N, Metter EJ, Bandinelli S, Lauretani F, Windham BG, Ferrucci L. Psychological, physical, and sensory correlates of fear of falling and consequent activity restriction in the elderly: the InCHIANTI study. Am J Phys Med Rehabil 2008; 87: 354-362.

26 Sakari R, Era P, Rantanen T, Leskinen E, Laukkanen P, Heikkinen E. Mobility performance and its sensory, psychomotor and musculoskeletal determinants from age 75 to age 80. Aging Clin Exp Res 2010; 22: 47-53.

27 Kearney PM, Cronin H, O'Regan C et al. Cohort profile: the irish longitudinal study on ageing. Int J Epidemiol 2011; 40: 877-884.

28 Beekman ATF, Deeg DJH, van Limbeek J, Braam AW, de Vries MZ, van Tilburg W. Criterion validity of the Center for Epidemiologic Studies Depression scale (CES-D): results from a community-based sample of older subjects in the Netherlands. Psychol Med 1997; 27: 231-235.

29 Reelick MF, van Iersel MB, Kessels RPC, Rikkert MGMO. The influence of fear of falling on gait and balance in older people. Age Ageing 2009; 38: 435-440.

30 Folstein MF, Folstein SE, McHugh PR. "Mini-mental state". A practical method for grading the cognitive state of patients for the clinician. J Psychiatr Res 1975; 12: 189-198.

31 Lezak MD, Howieson DB, Loring DW. Neuropsychological Assessment, 4th edn. New York: Oxford University Press, 2004.

32 Standardising JAR. Chronometery. Clocking the Mind: Mental Chronometry and Individual Differences. Amsterdam: Elsevier, 2006; 237-246.

33 Donoghue OA, Horgan NF, Savva GM, Cronin H, O'Regan C, Kenny RA. Association between timed up-and-go and memory, executive function, and processing speed. J Am Geriatr Soc 2012; 60: 1681-1686.

34 Rantanen T, Guralnik JM, Foley D et al. Midlife hand grip strength as a predictor of old age disability. JAMA 1999; 281: 558-560.

35 Podsiadlo D, Richardson S. The timed "Up \& Go": a test of basic functional mobility for frail elderly persons. $J$ Am Geriatr Soc 1991; 39: 142-148.

36 Klein BEK, Klein R, Lee KE, Cruickshanks KJ. Associations of performance-based and self-reported measures ofvisual function: the Beaver Dam Eye Study. Ophthalmic Epidemiol 1999; 6: 49-60.

37 Ferris FL, Kassoff A, Bresnick GH, Bailey I. New visual acuity charts for clinical research. Am J Ophthalmol 1982; 94: 91-96.

38 Colenbrander A. Visual standards, aspects and range of vision loss with emphasis on population surveys. Report prepared for the International Council of Ophthalmology at the 29th International Congress of Ophthalmology. Sydney, 2002. 
JOBNAME: No Job Name PAGE: 10 SESS: 9 OUTPUT: Wed Oct 9 15:41:42 2013 SUM: 176D488F

/Xpp84/wiley_journal/GGI/ggi_v0_i0/ggi_12174

OA Donoghue et al.

39 Hohberger B, Laemmer R, Adler W, Juenemann AG, Horn FK. Measuring contrast sensitivity in normal subjects with OPTEC 6500: influence of age and glare. Graefes Arch Clin Exp Ophthalmol 2007; 245: 1805-1814

40 Viljanen A, Kulmala J, Rantakokko M, Koskenvuo M, Kaprio J, Rantanen T. Fear of falling and coexisting sensory difficulties as predictors of mobility decline in older women. J Gerontol A Biol Sci Med Sci 2012; 67: 1230-1237.

41 Lord SR, Menz HB. Visual contributions to postural stability in older adults. Gerontology 2000; 46: 306-310.

42 Dhital A, Pey T, Stanford MR. Visual loss and falls: a review. Eye 2010; 24: 1437-1446.

43 Owsley C, Sekuler R, Siemsen D. Contrast sensitivity throughout adulthood. Vision Res 1983; 23: 689-699.
44 Glass JM. Visual function and cognitive aging: differential role of contrast sensitivity in verbal versus spatial tasks. Psychol Aging 2007; 22: 233-238.

45 Salthouse TA. The processing-speed theory of adult age differences in cognition. Psychol Rev 1996; 103: 403428

46 Madden DJ. Aging and visual attention. Curr Dir Psychol Sci 2007; 16: 70-74.

47 Anstey KJ, Wood J, Kerr G, Caldwell H, Lord SR. Different cognitive profiles for single compared with recurrent fallers without dementia. Neuropsychology 2009; 23: 500-508.

48 Owsley C, Sloane ME. Contrast sensitivity, acuity, and the perception of "real-world" targets. BrJ Ophthalmol 1987; 71: 791-796. 